\title{
Cable Tracking System Proposal
}

\author{
Nick Friedman \\ Experimental Facilities Division
}

\author{
DISCLAIMER
}

This report was prepared as an account of work sponsored by an agency of the United States Government. Neither the United States Government nor any agency thereof, nor any of their employees, makes any warranty, express or implied, or assumes any legal liability or responsibility for the accuracy, completeness, or usefulness of any information, apparatus, product, or process disclosed, or represents that its use would not infringe privately owned rights. Reference herein to any specific commercial product, process, or service by trade name, trademark, manufacturer, or otherwise does not necessarily constitute or imply its endorsement, recommendation, or favoring by the United States Government or any agency thereof. The views and opinions of authors expressed herein do not necessarily state or reflect those of the United States Government or any agency thereof.

\section{June 25, 1993}

\section{Advanced Photon Source Argonne National Laboratory}

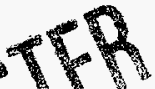




\section{DISCLAIMER}

Portions of this document may be illegible in electronic image products. Images are produced from the best available original document. 


\title{
CABLE TRACKING SYSTEM PROPOSAL
}

\author{
Nick Friedman \\ Experimental Facilities Division \\ Advanced Photon Source
}

October 19, 1992

\section{Introduction}

The Experimental Facilities Division requires a labeling system to identify and catalog the instrumentation, control, and computer cables that will run throughout the building. Tom Sheridan from the MIS Group has already made some general suggestions about the information that could be included in an Oracle-based Cable Tracking System (E-mail text distributed by Gary Gunderson on the 27th of August). Glenn Decker's LS Note No. 191 is also relevant to the subject since it addresses name assignment rules for the storage ring devices. The intent of this note is to recommend a mechanism for tracking wires/cables, with enough specifics, to which all groups in the Division would adhere when pulling cables.

Because most cables will run between various beamline devices, hutch safety components, and equipment racks, any method of tracking cables is related to the Equipment Tracking System. That system has been developed by the APS Project personnel and is described in the APS Project Equipment Tracking System Guidelines (DRAFT). It can be adopted to XFD's needs.

Two essential features of the Cable Tracking System are: 1) Each cable shell have a unique Identifier, and 2) Cable label must contain information that is helpful during troubleshooting in the field. The Identifier is an alphanumeric string of characters that will originate in the Oraclebased Cable Tracking System. It is not necessary for the identifier to carry a lot of intelligence its primary purpose is simply to provide a link to the database. Bar-coding the Identifier would make it easy to combine cable information with the Equipment Tracking System.

Oracle database, running under VAX/VMS operating system, is a multi-user project-wide system. As such, it will eliminate the possibility of duplicate entries. Additional benefits are expected from the ease of interface to the Equipment Tracking System, which is based in Oracle.

For the purpose of troubleshooting, it is very helpful to be able to access detailed cable data while working in any area of the experimental floor. A laptop computer equipped with an Ethernet interface card will provide such capability. 


\section{General Labeling Rules}

Each cable label will consist of three rows. The first row is the Cable Identifier assigned for each Group by the Oracle-based Cable Tracking System. The second row, System Identifier, states to which system the cable belongs, for example, PLC 1st Ph. Shutter or PLC FOE Rad. Safety. The third line, let's call it Location Identifier, identifies the source, destination, and termination type of the cable. More specific information about terminal block pins may be included on this line to facilitate quick location. All three lines can be customized to include additional information as found appropriate by the individual Groups - the System will prevent the use of duplicate Identifiers.

\section{Cable Labeling Standards}

1. Cable Identifier will consist of a two character group identifier followed by a six-digit number, for example, EC000221 or ID000093.

2. System Identifier is the second line, beneath the Cable Identifier. It describes to what system the cable belongs. This is an English description of what the cable is used for. For example, Connects $2 \mathrm{nd} \mathrm{Ph}$. Shutter to PLC, or Fast Valve Sensor to Controller (40 character $\max$.

3. Location Identifier, the third line on the label, will consist of two codes which refer to the point of origin and the location of the destination of the two ends of the cable. Each end of the cable is described by a seven-field code. The line will consist of two codes separated by a dash (-). An example of this line would be:

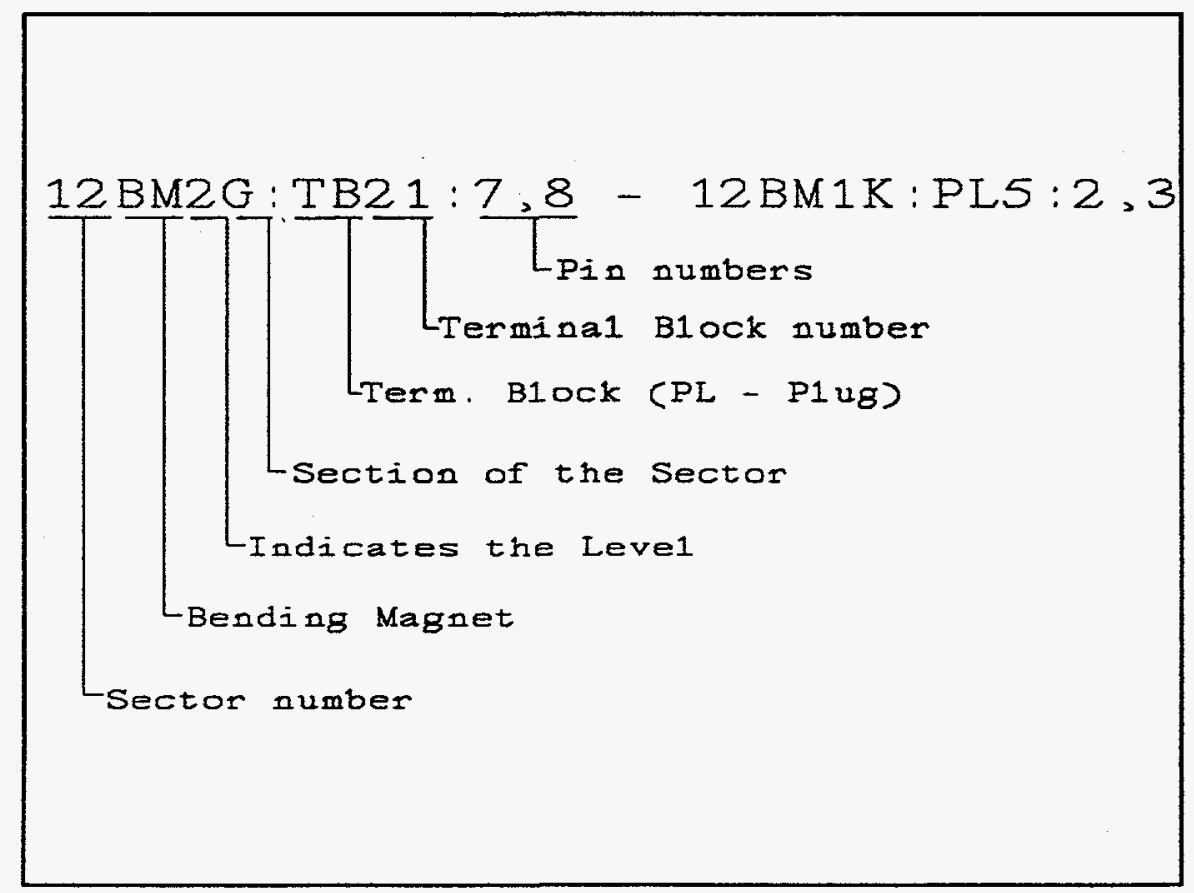

Fig. 1 
Below is an example of a cable labeled with this system:

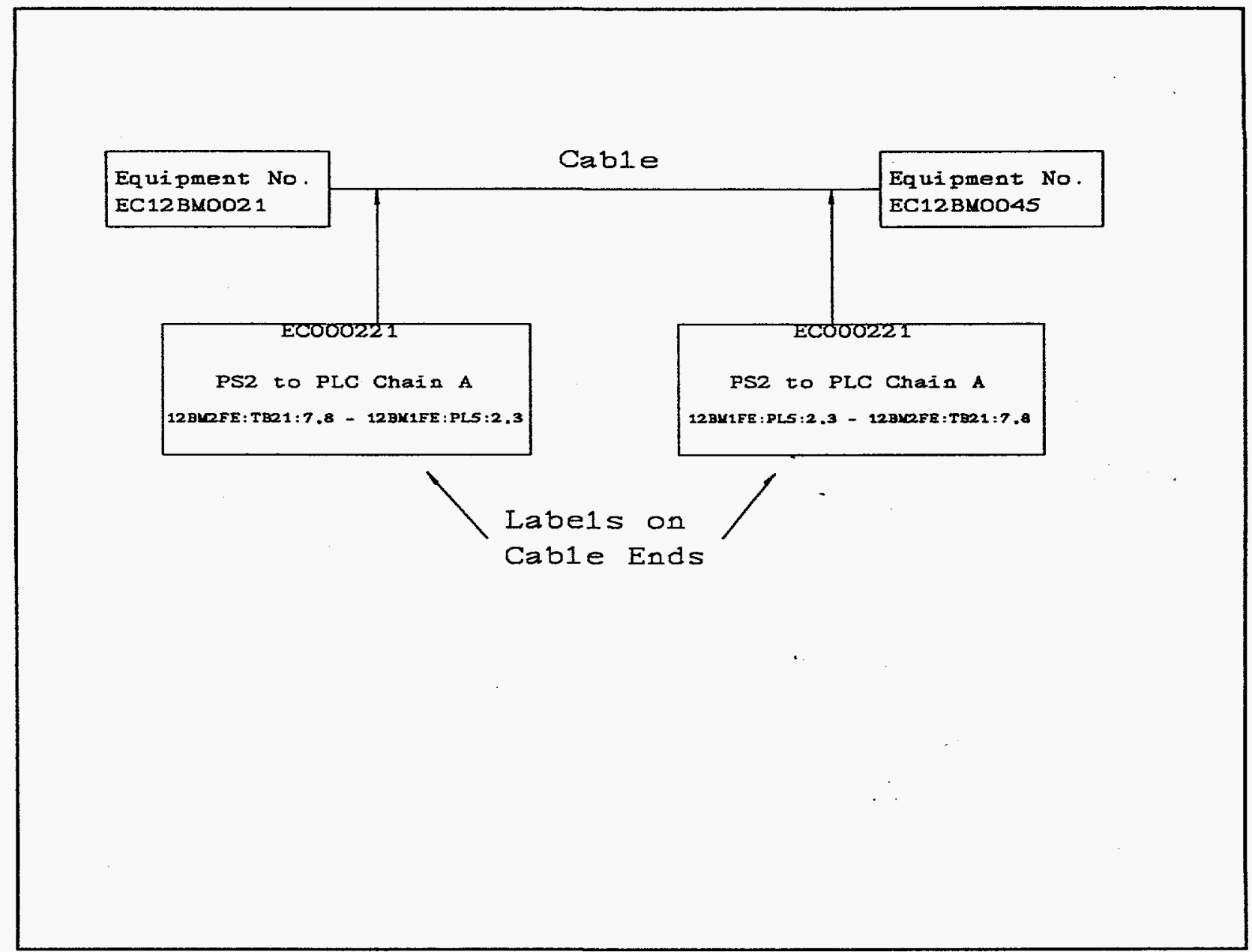

Fig. 2 
IV. Cable Definition Data Form

At this point, it is not necessary to establish strict procedures for pulling and labeling cables. However, it is important to emphasize that a Cable Definition Data Form must be filled out, to the extent possible, before actually pulling the cable. This Form has to be completed immediately after cable terminations are made. An example of such form is shown below.

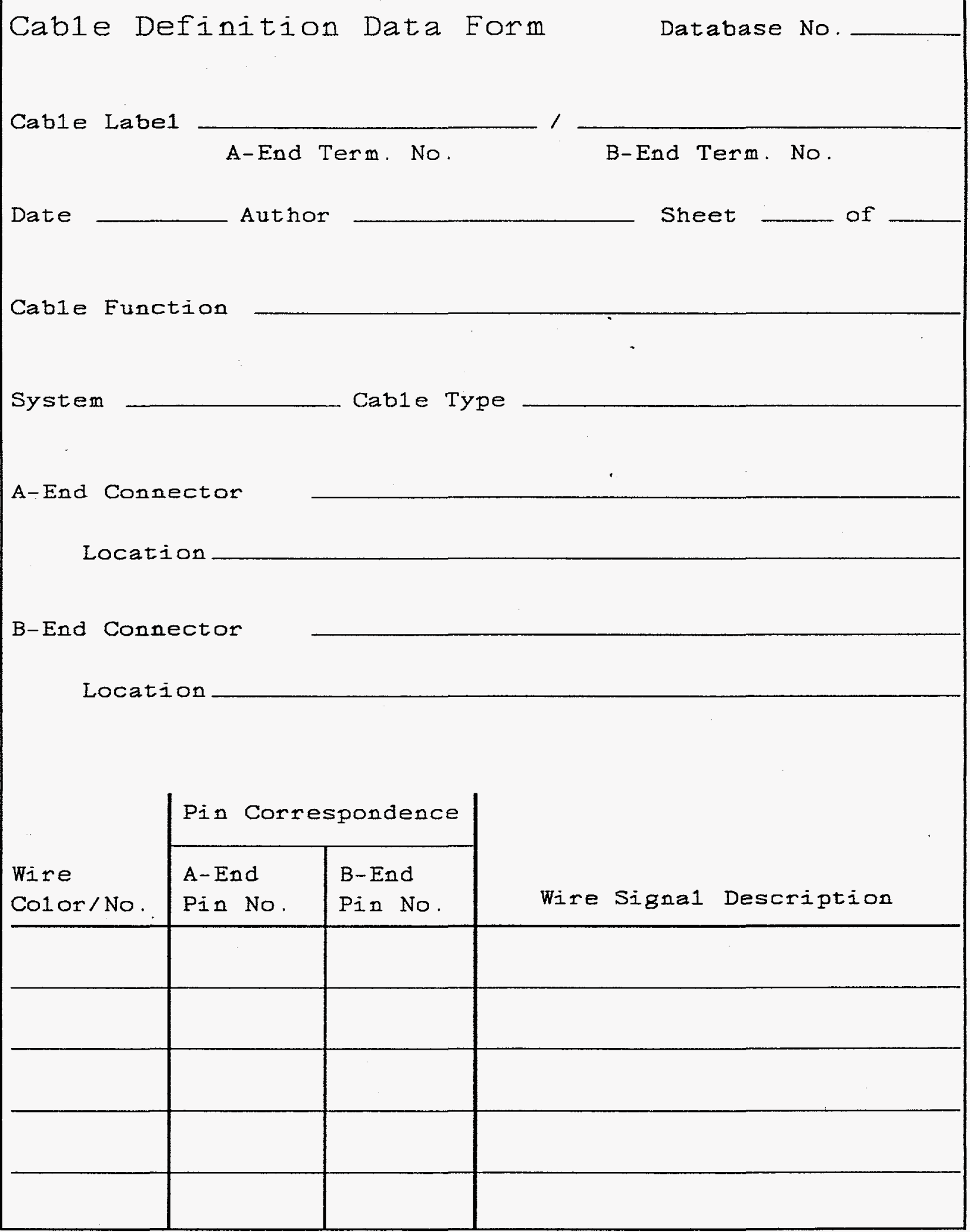

Fig. 4 


\section{Database Program}

The Cable Definition Data Form serves as the main source of information for entering data into the database system. Types of pertinent information to store in the database can be:

Cable Identifier Code

Cable Size

Number of Conductors

Wire Color Code

Insulation Material and Rating

Connector Type and Pin-out

Function

System Cable Serves

Resistance to Radiation

Date Installed

Wireway: Tray, Conduit Information

Drawings Numbers

Problems Observed

Comments

Etc. 